As shown in Table 1, racemate II was a more potent blocker of the cardiostimulant effects of Isp than either labetalol itself or racemate I. It was also more effective as $\beta_{2}$-receptor blocker than either labetalol or racemate I. Racemate I was the weakest among the three. Its activity was particularly weak in the tracheal preparations; out of 4 experiments, it produced antagonism only in 3 samples, probably because it produced a definite relaxation of this preparation. In contrast, $\alpha$-adrenoceptor blocking activity was more closely related with racemate $I$, the order of potency being racemate $I>$ labetalol $>$ racemate II. In any preparation, the $\mathrm{pA}_{2}$ values of labetalol approximated the algebraic mean of values of two racemates.

From these observations it is apparent that both racemates retain the $\alpha$ - and $\beta$-blocking activities of labetalol, although the $\alpha$-blocking activity is more closely related to racemate I, while the $\beta$-blocking activity is related to racemate II.

\title{
REFERENCES
}

1) Farmer, J.B., Kfnnedy, I., Levy, G.P. and Marshall, R.J.: Pharmacology of AH5158; a drug which blocks both $\alpha$ - and $\beta$-adrenoceptors. Brif. J. Pharmacol. 45, 660-675 (1972)

2) Hashimoto, K., Hashimoto, T., Iizuka, H., Tsukada, T., Matsuda, H. and Imai, S.: Hypotensive and vascular effects of labetalol in the normotensive rat and dog. Japan. Heart J. 19, 762-774 (1978)

3) Katano, Y., Takeda, K., Nakagawa, Y., Hashimoto, T., Nakazawa, M., Tsukada, T., OtORI, T. AND IMAI, S.: Folia pharmacol. japon. 74, 819-832 (1978) (Abs. in English)

4) Blinks, J.R. And Koch-Weser, J.: Physical factors in the analysis of the actions of drugs on myocardial contractility. Pharmacol. Rev. 15, 531-599 (1963)

\section{CATECHOLAMINES INDUCE NEUROGENIC VASODILATION BY INHIBITING GANGLIONIC TRANSMISSION IN SPINAL DOGS}

\author{
Kazushi KUSHIKU and Tatsuo FURUKAWA \\ Department of Pharmacology, School of Medicine, Fukuoka University, \\ Fukuoka 814, Japan
}

Accepted May 14, 1980

Catecholamines (CAs) affect functions of the innervated organ by acting not only on the adrenoceptors located in the sympathetic nerve ending as well as the innervated organ but also by acting on the ganglionic transmission. Since Marrazzi (1) first observed that epinephrine inhibited transmission in the superior cervical ganglion of the cat, this subject has been extensively investigated and CAs are now proposed to be capable of depressing ganglionic transmission $(2,3)$. In addition to inhibition of the transmission by CAs, CAs exert facilitatory actions on the atropine-sensitive postganglionic firing evoked by anticholinesterase agents and muscarinic stimulants (4). For these proposals, electro- 
physiological technics have been extensively worked out; changes in ganglionic surface potential or postganglionic discharge were utilized as an index for ganglionic responses to CAs in the isolated ganglia and in vivo experiments. However, an appropriate study, in which functional changes in the innervated peripheral organ are observed as an indicator of ganglionic function, should provide additional verification regarding the ganglionic effect of CAs. As for peripheral blood vessels, CAs constrict the vessels through stimulation of postsynaptic $\alpha$ receptors. However, it has not been clearly demonstrated whether CAs can dilate the blood vessels by affecting the ganglionic functions. The present study was an attempt to investigate the in vivo direct effect of CAs, administered to the inferior mesenteric ganglion through the artery, on the vascular tone of the inferior mesenteric artery in spinal dogs.

Mongrel dogs of either sex weighing between 15 and $29 \mathrm{~kg}$ were anesthetized with $35 \mathrm{mg} / \mathrm{kg}$ of pentobarbital sodium administered i.p. The animals were respired with air by means of a ventilator (KN-50, Natsume) (24 strokes $/ \mathrm{min}, 300 \mathrm{ml}$ tidal volume). Both vagi were cut in the cervical region and the right artery was ligated. To eliminate reflex changes in the autonomic activity, the spinal cord in all animals was severed with a scalpel through the atlanto-occipital foramen. The surgical procedures were as reported previously(5) After the left flank was opened, the inferior mesenteric artery was perfused by means of an appropriate tubing placed between the proximal portion of the left carotid artery and the distal portion of the inferior mesenteric artery, using an interposed sigmamotor pump. The flow was adjusted and the pump speed was maintained constant during the experiment so that the perfusion pressure approximated the normal blood pressure in the inferior mesenteric artery. The inferior mesenteric artery was then cannulated retrogradely close to the inferior mesenteric ganglion with a polyethylene catheter connected to a stopcock, and the catheter was tightly secured in place.

Since ganglionic transmission in the inferior mesenteric ganglion was decreased by transection of the spinal cord which lowers impulse flow, the left preganglionic nerve to the inferior mesenteric ganglion was stimulated continuously with an electric stimulator (MSE3R, Nihon Kohden). The parameters of stimulation were; square wave pulses, $1 \mathrm{msec}$ duration, frequencies, $10 \mathrm{~Hz}$ in the inferior mesenteric ganglion, with supramaximal voltage ranging from 15 to $20 \mathrm{~V}$. In order to avoid outflow of the injected drug solution into the aorta, the agents were slowly injected over 20-30 sec through a catheter inserted previously into the inferior mesenteric artery. The volume of i.a. administered drugs was from 0.1 to $0.2 \mathrm{ml}$. Epinephrine (E) and dopamine (DA) were dissolved in $0.01 \mathrm{~N} \mathrm{HCl}$, and diluted with $0.9 \%$ sodium chloride before injection. All doses of drugs were expressed in terms of their base. As control studies, saline or $0.01 \mathrm{~N} \mathrm{HCl}$ solution $(0.1 \mathrm{ml})$ diluted with saline was injected i.a. during preganglionic stimulation, but the perfusion pressure was not altered by these injections.

As shown in Fig. 1, E $(0.4 \mu \mathrm{g})$ injected into the inferior mesenteric artery during preganglionic stimulation $(10 \mathrm{~Hz}, 1 \mathrm{msec}, 15 \mathrm{~V})$ induced a fall of perfusion pressure without producing changes in systemic blood pressure. The original values had not been reverted to 


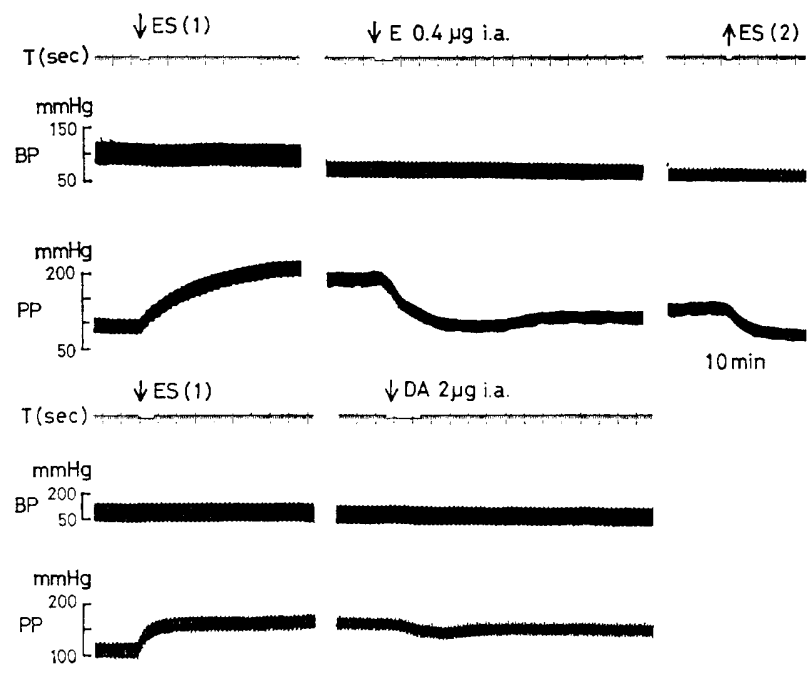

FIG, 1. Effects on inferior mesenteric perfusion pressure of epinephrine and dopamine injected into the arterial supply of the inferior mesenteric ganglion during preganglionic stimulation. The parameters of the preganglionic stimulation are square wave pulses of $1 \mathrm{msec}$ duration at a frequency of $10 \mathrm{~Hz}$ and supramaximal voltage. ES (1) indicates the beginning of the preganglionic stimulation and ES (2) the end of the stimulation period. The upper panel shows the effect of epinephrine, the lower panel that of dopamine. BP; systemic arterial blood pressure, PP: inferior mesenteric perfusion pressure, $\mathrm{T}$; time base marking every one second.

within 10 min after the injection. DA $(2 \mu \mathrm{g})$ injected in the same way produced a similar fall but the effect was weaker than $\mathrm{E}(0.4 / \mathrm{g})$ in decreasing the perfusion pressure. The average fall in inferior mesenteric perfusion pressure induced by $\mathrm{E}$ and DA was $74 \pm 9.3$ and $31 \pm 6.4 \mathrm{~mm} \mathrm{Hg}$, respectively, in three spinal dogs of which an average perfusion pressure rose from the control $90 \mathrm{mmHg}$ to $180 \mathrm{mmHg}$ by continuous preganglionic stimulation. Neither an injection of the same dose of CAs into the inferior mesenteric artery in the absence of continuous preganglionic stimulation nor a systemic administration to the femoral vein exhibited a fall in the perfusion pressure.

As reported in our previous paper, the agents administered into the artery in this fashion reach the inferior mesenteric ganglion at effective concentrations and affect the peripheral functions through the sympathetic system (5). In the present study, E and DA administered i.a. during preganglionic stimulation produced a marked mesenteric vasodilation. These findings support the previous results obtained from electrophysiological studies that CAs inhibit ganglionic transmission in the inferior mesenteric and paraverbetral lumbar ganglia of the $\operatorname{dog}(6,7)$. Although a dose response study was not done, E seemed to be more potent than DA. These observations are in agreement with findings by Libet and Kobayashi (8) in which E, and to a lesser extent norepinephrine and DA, elicits a hyperpolarizing response in the curarized and nicotinized ganglia of the frog. Thus, it has been clearly demonstrated that CAs dilate blood vessels by inhibiting ganglionic transmission. 


\title{
REFERENCES
}

1) MarrazzI, A.S.: Electrical studies on the pharmacology of autonomic synapses. II. The action of sympathomimetic drugs (epinephrine) on sympathetic ganglia. J. Pharmacol. exp. Ther. 65, 395-404 (1939)

2) Phillis, J.W.: The pharmacology of autonomic ganglia. In: The Pharmacology of Synapses, Edited by J.W. Phillis, pp. 123-148, Pergamon Press, London, (1970)

3) Willems, J.L.: On the pharmacology of autonomic ganglia. Arch. int. Pharmacodyn. 196, 244-257 (1972)

4) DeGroat, W.C.: Actions of the catecholamines in sympathetic ganglia. Circulation Res. 20-21, Supp. 3, 135-145 (1967)

5) Kushiku, K., Ichimasa, S., Kamiya, H. and Furukawa, T.: In vivo direct effects of cholinergic agents on the inferior mesenteric and cardiac ganglia with relation to their receptors in the dog. Japan. J. Pharmacol. 29, 763-774 (1979)

6) LINS, R.L. AND WILLEMS, J.L.: Dopamine-induced inhibition of synaptic transmission in the inferior mesenteric ganglion of the dog. Arch. int. Pharmacodyn. 208, 367-368 (1974)

7) Willems, J.L.: Dopamine-induced inhibition of synaptic transmission in lumbar paravertebral ganglia of the dog. Arch. Pharmacol. 279, 115-126 (1973)

8) Libet, B. AND KoBayashi, H.: Adrenergic mediation of slow inhibitory postsynaptic potential in sympathetic ganglia of the frog. J. Neurophysiol. 37, 805-814 (1974)

\section{ACTIVATION BY PHOSPHOLIPASE $\mathrm{A}_{2}$ OF THE CATECHOLAMINE RELEASE FROM ISOLATED CHROMAFFIN GRANULES}

\author{
Futoshi IZUMI, Yumiko TOYOHIRA, Takeshi KASHIMOTO, \\ Akihiko WADA and Motoo OKA* \\ Department of Pharmacology, School of Medicine, University of Occupational \\ and Environmental Health, Kita-Kyushu, Fukuoka 807, Japan \\ * Department of Pharmacology, Tokushima University, School of Medicine. \\ Kuramoto-3, Tokushima 770, Japan
}

Accepted May 15, 1980

Lipid composition of the adrenal chromaffin granules was studied by Blaschko et al. (1) and Winkler et al. (2). These workers found an unusually high content of lysophosphatidylcholine (LPC) in chromaffin granules which proved to be derived from granule membrane (3). The high content of LPC has been causally related to the release mechanism of catecholamine (4). It is well established that release of catecholamine is brought about by exocytosis (5-8) and LPC in chromaffin granules was assumed to promote the fusion of granules with plasma membrane (4).

Taugner and Wähler (9) reported the effects of lipid-modification on catecholamine release in isolated chromaffin granules. Digestion of the chromaffin granules with naja naja phospholipase A produced an instantaneous liberation of $90 \%$ of the stored catecholamines. They assumed that enhancement of catecholamine release may be due to an increased fluidity in the membrane protein. 